\title{
Comparison of best versus worst clinical outcomes for adult spinal deformity surgery: a retrospective review of a prospectively collected, multicenter database with 2-year follow-up
}

\author{
Presented at the 2015 AANS/CNS Joint Section on Disorders of the Spine and Peripheral Nerves \\ Justin S. Smith, MD, PhD, ${ }^{1}$ Christopher I. Shaffrey, MD, ${ }^{1}$ Virginie Lafage, $\mathrm{PhD},{ }^{2}$ \\ Frank Schwab, MD, ${ }^{2}$ Justin K. Scheer, BS, ${ }^{3}$ Themistocles Protopsaltis, MD, ${ }^{2}$ \\ Eric Klineberg, MD, ${ }^{4}$ Munish Gupta, MD, ${ }^{4}$ Richard Hostin, MD, ${ }^{5}$ Kai-Ming G. Fu, MD, PhD, ${ }^{6}$ \\ Gregory M. Mundis Jr., MD, ${ }^{7}$ Han Jo Kim, MD, ${ }^{8}$ Vedat Deviren, MD, ${ }^{9}$ Alex Soroceanu, MD, ${ }^{2}$ \\ Robert A. Hart, MD, ${ }^{10}$ Douglas C. Burton, MD, ${ }^{11}$ Shay Bess, MD, ${ }^{12}$ Christopher P. Ames, MD, ${ }^{13}$ \\ and the International Spine Study Group
}

\begin{abstract}
${ }^{1}$ Department of Neurosurgery, University of Virginia Medical Center, Charlottesville, Virginia; '2Department of Orthopaedic Surgery, NYU Hospital for Joint Diseases; ${ }^{6}$ Department of Neurosurgery, Weill Cornell Medical College; ${ }^{8}$ Department of Orthopaedic Surgery, Hospital for Special Surgery, New York, New York; '3Department of Neurological Surgery, Northwestern University, Chicago, Illinois; ${ }^{4}$ Department of Orthopaedic Surgery, University of California Davis, Sacramento; ${ }^{7}$ San Diego Center for Spinal Disorders, La Jolla, California; 'Department of Orthopaedic Surgery, Baylor Scoliosis Center, Plano, Texas; Departments of ${ }^{9}$ Orthopaedic Surgery and ${ }^{13}$ Neurosurgery, University of California San Francisco, California; ${ }^{10}$ Department of Orthopaedic Surgery, Oregon Health \& Science University, Portland, Oregon; ${ }^{11}$ Department of Orthopaedic Surgery, University of Kansas Medical Center, Kansas City, Kansas; and ${ }^{12}$ Department of Orthopaedic Surgery, Rocky Mountain Hospital for Children, Denver, Colorado
\end{abstract}

OBJECT Although recent studies suggest that average clinical outcomes are improved following surgery for selected adult spinal deformity (ASD) patients, these outcomes span a broad range. Few studies have specifically addressed fac-

ABBREVIATIONS ASA = American Society of Anesthesiology; $\mathrm{ASD}=$ adult spinal deformity; $\mathrm{BMI}=$ body mass index; $\mathrm{CCl}=\mathrm{Charlson}$ Comorbidity Index; $\mathrm{EBL}=$ estimated blood loss; HRQOL = health-related quality of life; ISSG = International Spine Study Group; LL = lumbar lordosis; ODI = Oswestry Disability Index; PI = pelvic incidence; PT = pelvic tilt; SDSG = Spinal Deformity Study Group; SF-36 = 36-Item Short Form Health Survey; SRS-22 = Scoliosis Research Society-22 Patient Questionnaire; SVA = sagittal vertical axis.

SUBMITTED August 2, 2014. ACCEPTED December 30, 2014.

INCLUDE WHEN CITING Published online June 5, 2015; DOI: 10.3171/2014.12.SPINE14777.

DISCLOSURE The ISSG is funded through research grants from DePuy Synthes and individual donations. Dr. Smith reports being a consultant for Biomet, NuVasive, Cerapedics, Medtronic, and DePuy; receiving clinical or research support from DePuy/ISSG Foundation (ISSGF) for the study described; and receiving support from DePuy/ ISSGF for non-study-related clinical or research effort. Dr. Shaffrey reports being a consultant for Biomet, Globus, Medtronic, NuVasive, and Stryker and holding patents with and receiving royalties from Biomet, Medtronic, and NuVasive. Dr. Lafage reports being a consultant for MSD; direct stock ownership in Nemaris, Inc.; receiving support from DePuy, SRS, ISSGF, and NIH for non-study-related clinical or research effort; and being a speaker/teacher for DePuy, K2M, NuVasive, and Nemaris, Inc. Dr. Schwab reports being a consultant for MSD, K2M, DePuy, and Medicrea; direct stock ownership in Nemaris, Inc.; holding patents with MSD, Nemaris, K2M, and NuVasive; receiving support from DePuy, MSD, and AO for non-study-related clinical or research effort; and being a speaker/teacher for MSD, Nemaris, Inc., and K2M. Dr. Protopsaltis reports being a consultant for Medicrea and Biomet Spine and receiving support from Zimmer Spine for non-study-related clinical or research effort. Dr. Klineberg reports receiving speaker fees and/or a fellowship grant from DePuy Synthes, AO Spine, and OREF. Dr. Gupta reports direct stock ownership in Johnson \& Johnson, Proctor \& Gamble, Pfizer, and Pioneer; being a consultant for DePuy Synthes, Medtronic, and Medicrea; receiving royalties from DePuy Synthes; and being a board member and/or treasurer of SRS and FOSA. Dr. Hostin reports being a consultant for DePuy and receiving support from NuVasive, Seeger, DJO, DePuy, and K2M for non-study-related clinical or research effort. Dr. Fu reports being a consultant for Medtronic and DePuy. Dr. Mundis reports being a consultant for NuVasive and K2M; receiving support from NuVasive for non-study-related clinical or research effort; and receiving royalties from NuVasive and K2M. Dr.Kim reports being a consultant for, member of speaker bureau of, and/ or receiving traveling expense fees from DePuy, Stryker, Biomnet, K2M, and Medtronic. Dr. Deviren reports being a consultant for NuVasive, Guidepoint, and Stryker and reports UCSF received fellowship grant support from AO Spine, Globus, and NuVasive. Dr. Hart reports being a consultant for DePuy Synthes, Globus, and Medtronic; direct stock ownership in Spine Connect; holding a patent with OHSU; receiving support from Medtronic and ISSGF for non-study-related clinical or research effort; and receiving royalties and/or speaker bureau/paid honoraria from Seaspine and DePuy Synthes. Dr. Burton reports being a consultant for and holding a patent with DePuy Spine and receiving clinical or research support from DePuy Spine for the study described. Dr. Bess reports being a consultant for K2M and Allosource; receiving clinical or research support from DePuy Synthes for the study described; and receiving support from Medtronic and K2M for non-study-related clinical or research effort. Dr. Ames reports being a consultant for DePuy, Medtronic, and Stryker; direct stock ownership in Doctors Research Group and Biomet Spine; holding a patent with Fish \& Richardson, P.C.; and receiving royalties from Aesculap and Baxano Surgery. 
tors that may predict favorable clinical outcomes. The objective of this study was to compare patients with ASD with best versus worst clinical outcomes following surgical treatment to identify distinguishing factors that may prove useful for patient counseling and optimization of clinical outcomes.

METHODS This is a retrospective review of a prospectively collected, multicenter, database of consecutively enrolled patients with ASD who were treated operatively. Inclusion criteria were age $>18$ years and ASD. For patients with a minimum of 2-year follow-up, those with best versus worst outcomes were compared separately based on Scoliosis Research Society-22 (SRS-22) and Oswestry Disability Index (ODI) scores. Only patients with a baseline SRS-22 $\leq 3.5$ or $\mathrm{ODI} \geq 30$ were included to minimize ceiling/floor effects. Best and worst outcomes were defined for SRS-22 ( $\geq 4.5$ and $\leq$ 2.5 , respectively) and ODI ( $\leq 15$ and $\geq 50$, respectively).

RESULTS Of 257 patients who met the inclusion criteria, 227 (88\%) had complete baseline and 2-year follow-up SRS22 and ODI outcomes scores and radiographic imaging and were analyzed in the present study. Of these 227 patients, 187 had baseline SRS-22 scores $\leq 3.5$, and 162 had baseline ODI scores $\geq 30$. For the SRS-22, best and worst outcomes criteria were met at follow-up for 25 and 27 patients, respectively. For the ODI, best and worst outcomes criteria were met at follow-up for 43 and 51 patients, respectively. With respect to the SRS-22, compared with best outcome patients, those with worst outcomes had higher baseline SRS-22 scores $(p<0.0001)$, higher prevalence of baseline depression $(p<0.001)$, more comorbidities $(p=0.012)$, greater prevalence of prior surgery $(p=0.007)$, a higher complication rate $(p=0.012$ ), and worse baseline deformity (sagittal vertical axis [SVA], $p=0.045$; pelvic incidence $[P I]$ and lumbar lordosis [LL] mismatch, $p=0.034)$. The best-fit multivariate model for SRS-22 included baseline SRS-22 ( $p=$ $0.033)$, baseline depression ( $p=0.012)$, and complications $(p=0.030)$. With respect to the ODI, compared with best outcome patients, those with worst outcomes had greater baseline ODI scores $(p<0.001)$, greater baseline body mass index (BMI; $p=0.002)$, higher prevalence of baseline depression $(p<0.028)$, greater baseline SVA $(p=0.016)$, a higher complication rate $(p=0.02)$, and greater 2-year SVA $(p<0.001)$ and PI-LL mismatch $(p=0.042)$. The best-fit multivariate model for ODI included baseline ODI score $(p<0.001)$, 2-year SVA $(p=0.014)$ and baseline BMI $(p=0.037)$. Age did not distinguish best versus worst outcomes for SRS-22 or ODI ( $p>0.1)$.

CONCLUSIONS Few studies have specifically addressed factors that distinguish between the best versus worst clinical outcomes for ASD surgery. In this study, baseline and perioperative factors distinguishing between the best and worst outcomes for ASD surgery included several patient factors (baseline depression, BMI, comorbidities, and disability), as well as residual deformity (SVA), and occurrence of complications. These findings suggest factors that may warrant greater awareness among clinicians to achieve optimal surgical outcomes for patients with ASD.

http://thejns.org/doi/abs/10.3171/2014.12.SPINE14777

KEY WORDS adult spinal deformity; complications; depression; sagittal alignment; pelvic parameters; surgery; outcomes

A DULTS with spinal deformity characteristically present with pain and disability. $6,8,10,18,19,22,37,42-44,46,47,49$, 51,52 In the absence of significant or progressive neurological deficit, first-line treatments for symptomatic adult spinal deformity (ASD) are typically nonoperative and may include physical therapy, steroid injections, nonsteroidal antiinflammatory drugs, and, potentially, narcotics.,48 For patients who do not achieve a satisfactory response with nonoperative approaches, surgical treatment may become an option.

Recent studies have suggested that operative treatment for selected patients with ASD has the potential to provide significant relief of pain and disability, especially when compared with nonoperative treatments. , $10,23,43,49$ However, the complication rates associated with these procedures are not insignificant, with reported rates ranging from $10 \%$ to more than $80 \% .^{10,43,49}$ Both the surgeon and the patient must carefully weigh the risks of surgical treatment versus the potential benefits in deciding whether surgical treatment is appropriate and worthwhile to pursue. An important part of this risk-benefit analysis and of patient counseling is the discussion regarding reasonable expectations.

Previous reports suggest that surgery for selected patients with ASD can provide approximately $60 \%$ relief of back and leg pain and approximately $40 \%$ improvement in disability at 2-year follow-up compared with baseline lev- els. ${ }^{46,47}$ Although these results offer simple objective measures that may be useful for patient counseling, it is important to recognize that they are based on averages of large groups of patients with wide ranges of spinal deformities, symptoms, and health states. Certainly not all patients will achieve the average improvements in pain and disability, and at the opposing extremes of the spectrum of clinical outcomes are those who are fortunate to be left with very limited or even no residual symptoms and those with the misfortune of having no improvement of symptoms or potentially even worsened symptoms and disability. ${ }^{50}$ Assessing and comparing the patients at these opposing ends of the outcomes scales may provide insight into important factors for optimization of patient outcomes.

Our objectives in the present study were to define the ranges of outcomes for ASD surgery based on standardized health-related quality of life (HRQOL) measures and to assess for factors that may distinguish between those patients with the best and worst clinical outcomes.

\section{Methods}

\section{Patient Population}

This is a retrospective review of a prospectively collected, multicenter database of consecutively enrolled patients with ASD collected through the International Spine 
Study Group (ISSG), which is composed of 11 sites across the United States. Patients were enrolled at each site after institutional review board approval. Inclusion criteria for the ISSG database are age $>18$ years and presence of at least 1 of the following measures of spinal deformity: scoliosis Cobb angle $\geq 20^{\circ}$, sagittal vertical axis (SVA) $\geq$ $5 \mathrm{~cm}$, pelvic tilt $(\mathrm{PT}) \geq 25^{\circ}$, and thoracic kyphosis $\geq 60^{\circ}$. Only patients treated surgically were included in the present study. In addition, only patients with available baseline and 2-year follow-up outcomes measures and radiographic data were included in the analyses.

\section{Data Collection and Radiographic Assessment}

Data collection at baseline and at 2 years following surgical treatment included standardized HRQOL questionnaires as well as clinical, demographic, and radiographic information. Standardized HRQOL questionnaires included the Oswestry Disability Index (ODI) ${ }^{16}$ the Scoliosis Research Society-22 Patient Questionnaire (SRS-22), ${ }^{9}$ and the 36-Item Short Form Health Survey (SF-36). ${ }^{53} \mathrm{Ba}-$ sic demographic and clinical data included patient age, sex, body mass index (BMI), Charlson Comorbidity Index (CCI), ${ }^{13}$ American Society of Anesthesiology (ASA) grade, history of prior spine surgery, smoking status at baseline, and diagnosis of depression at baseline. In addition, a numeric rating scale score ranging from 0 to 10 for back and leg pain was collected, with 0 representing no pain and 10 reflecting the most unbearable pain. Surgical data were extracted from standardized data collection sheets and included surgical approach, number of posterior levels operated on, operating room time, and estimated blood loss (EBL). Information regarding complications, including those occurring intraoperatively and through the time of last follow-up, was collected and classified as minor or major, as recommended by Carreon et al. ${ }^{11}$

Full-length, free-standing anteroposterior and lateral spine radiographs (36-inch cassette) obtained at baseline and at follow-up were analyzed using validated software $^{12,34}$ (Spineview; ENSAM Laboratory of Biomechanics). All radiographic measurements were performed at a central location (NYU Hospital for Joint Disease), based on standard techniques, ${ }^{3,33}$ and included coronal Cobb angle, global coronal alignment (based on the offset of the C-7 plumb line relative to the central sacral vertical line), lumbar lordosis (LL; Cobb angle between superior endplate of L-1 and superior endplate of S-1), SVA (C-7 plumb line relative to S-1), PT, pelvic incidence (PI), and mismatch between PI and LL (PI-LL mismatch). For patients with a coronal Cobb angle of at least $10^{\circ}$, curve type (upper thoracic, thoracic, or thoracolumbar/lumbar) was categorized based on the curve with the maximum Cobb angle.

\section{Data and Statistical Analysis}

Patients with the best and worst clinical outcomes were identified separately based on the ODI and SRS-22 outcomes measures. The cut-offs for the best and worst outcomes for the ODI and SRS-22 scores were based on assessment of distribution plots for each outcome measure, with specific focus on the tails at the extremes (best and worst) and previously reported score correlates to health states. ${ }^{5,16,17}$ For each outcomes measure, patients with the best and worst outcomes were compared based on demographic, clinical, radiographic, and surgical parameters. To minimize floor effects of the ODI, comparisons of best versus worst clinical outcomes were based on patients with a baseline ODI of at least 30. Similarly, to minimize the ceiling effects of the SRS-22, comparisons of best versus worst clinical outcomes were based on patients with a baseline SRS-22 $\leq 3.5$. These baseline cutoffs of ODI and SRS-22 were selected to reflect values corresponding to thresholds of moderate disability based on previous reports. . $^{5,16,17}$

Frequency distributions and summary statistics were calculated for all demographic, clinical, operative, and radiographic variables. For categorical variables, crosstabulations were generated and Fisher's exact or Pearson chi-square tests were used to compare distributions. For continuous variables, unpaired t-tests were used to assess differences in the distributions between subsets of patients classified by categorical data, and paired t-tests were used to assess differences in means for the same cohort between baseline and 2-year follow-up time points. Binary logistic regression analysis was used to adjust for the effects of multiple covariates predictive of best versus worst outcomes. Forward stepwise regression analyses used variables with $\mathrm{p}<0.1$ for statistical assessment for capacity to distinguish between patients with best versus worst outcomes on univariate assessments. Statistical analyses were 2-sided, and $\mathrm{p}<0.05$ was considered statistically significant.

\section{Results \\ Patient Population}

Of 257 patients who met inclusion criteria, 227 (88\%) had complete baseline and 2-year follow-up SRS-22 and ODI outcomes scores and radiographic imaging and were included in the present study. Of these 227 patients, 187 had baseline SRS-22 scores $\leq 3.5$, and 162 had baseline ODI scores $\geq 30$. Demographic, clinical, and operative parameters for these 227 patients are summarized in Table 1 . Their mean age was 55 years, and $84 \%$ of the patients were women. The mean BMI was 27 ("overweight") and ranged from 17 ("moderate thinness") to 54 ("Class III obesity). ${ }^{54}$ Mean CCI and ASA grade were 1.4 and 2.2, respectively, and at baseline, $25 \%$ of the patients had a diagnosis of depression and $10 \%$ were active smokers. Curve types, based on maximum Cobb angle, were relatively evenly distributed across upper thoracic (34\%), thoracic (27\%), and thoracolumbar/lumbar (39\%) regions. Nearly all patients (97\%) underwent a posterior surgical procedure, and the mean number of levels operated on was 10 . Anterior and lateral interbody procedures were performed in $28 \%$ and $7 \%$ of patients, respectively. The overall minor and major complication rates were $53 \%$ and $40 \%$, respectively.

The mean preoperative and 2-year follow-up HRQOL scores and radiographic measures for the entire study cohort of 227 patients are summarized in Table 2. Compared with baseline, all measures of HRQOL improved at 2-year follow-up, including ODI, SRS-22, and back and leg pain scores. Similarly, the cohort demonstrated significant improvement in measures of coronal and sagittal deformity, 
TABLE 1. Demographic, clinical, and operative parameters for 227 surgically treated adults with spinal deformity

\begin{tabular}{lc}
\hline \multicolumn{1}{c}{ Parameter } & \multicolumn{1}{c}{ Value } \\
\hline F/M & $191: 36$ \\
\hline Mean age, yrs (SD, range) & $55(15,19-84)$ \\
\hline Mean BMI (SD, range) & $27(6,17-54)$ \\
\hline Mean CCI (SD, range) & $1.4(1.5,0-8)$ \\
\hline Mean ASA grade (SD, range) & $2.2(0.7,1-4)$ \\
\hline Depression/anxiety (\%) & 25 \\
\hline Smoker (\%) & 10 \\
\hline Curve type (\%) & \\
\hline Upper thoracic & 34 \\
\hline Thoracic & 27 \\
\hline Thoracolumbar/lumbar & 39 \\
\hline No. of posterior procedures (\%) & $221(97)$ \\
\hline Mean no. of levels (SD, range) & $10(4,2-17)$ \\
\hline No. of anterior interbody procedures (\%) & $64(28)$ \\
\hline No. of lateral interbody procedures (\%) & $16(7)$ \\
\hline Mean operating room time, hrs (SD, range) & $7.4(2.9,2.3-18.9)$ \\
\hline Mean estimated blood loss, L (SD, range) & $2.0(1.7,0.2-12.2)$ \\
\hline No. of minor complications (\%) & $121(53)$ \\
\hline No. of major complications (\%) & $91(40)$ \\
\hline Percentages based $\%$ the number & \\
\hline
\end{tabular}

* Percentages based on the number of patients with a coronal Cobb angle of at least $10^{\circ}(n=219)$.

including maximum coronal Cobb angle, global coronal alignment, SVA, PT, and PI-LL.

\section{Best and Worst Outcomes Based on ODI}

Of the 227 patients in the study cohort, $162(71 \%)$ had a baseline ODI score $\geq 30$. For these 162 patients, the mean baseline ODI score was 51 (SD 13, range 31-86) and the mean 2-year ODI score was 31 (SD 20, range 0-82) (Fig. 1 left). Based on the ODI, the best outcome group (ODI score $\leq 15)$ consisted of $43(27 \%)$ patients and the worst outcome group (ODI score $\geq 50)$ consisted of $51(31 \%)$ patients (Fig. 1 left). The worst outcome group had a mean baseline ODI score of 59 (SD 14) and a mean 2-year follow-up ODI score of 55 (SD 9) (Fig. 2 left). In contrast, the best outcome group had a mean baseline ODI score of 43 (SD 9) that improved to a mean of 7 (SD 5) at 2-year follow-up (Fig. 2 left).

Univariate comparisons between the patients with best versus worst outcomes based on the ODI are summarized in Table 3. Compared with best outcome patients, at baseline those with worst outcomes had worse ODI $(p<0.001)$, SRS-22 ( $p<0.001)$, SRS-22 mental ( $p<0.001)$, and SF-36 mental component $(\mathrm{p}<0.001)$ scores and had more back pain $(\mathrm{p}=0.003)$, greater BMI $(\mathrm{p}=0.002)$, higher prevalence of depression $(p=0.028)$, higher prevalence of positive sagittal malalignment $(\mathrm{p}=0.009)$, and a trend toward worse PI-LL mismatch ( $\mathrm{p}=0.063)$. Notably, best versus worst outcome groups did not differ significantly based on mean age (57 years vs 60 years, respectively, $\mathrm{p}=0.138$ ), CCI $(p=0.082)$, or smoking status $(p=0.247)$. Mean operative time and EBL did not differ significantly between
TABLE 2. Radiographic and clinical outcomes at baseline and at 2-year follow-up for 227 operatively treated adults with spinal deformity

\begin{tabular}{|c|c|c|c|}
\hline Parameters & Preoperative & $\begin{array}{c}2-Y r \\
\text { Follow-Up }\end{array}$ & p Value* \\
\hline Mean ODI score (SD) & $41(19)$ & $25(20)$ & $<0.001$ \\
\hline Mean SRS-22 score (SD) & $2.9(0.7)$ & $3.7(0.8)$ & $<0.001$ \\
\hline Mean back pain score (SD) & $7.0(2.3)$ & $3.4(3.1)$ & $<0.001$ \\
\hline Mean leg pain score (SD) & $4.2(3.4)$ & $2.4(2.9)$ & $<0.001$ \\
\hline $\begin{array}{l}\text { Mean maximum Cobb angle, } \\
{ }^{\circ}(\mathrm{SD})\end{array}$ & $45(21)$ & $26(20)$ & $<0.001$ \\
\hline $\begin{array}{l}\text { Mean coronal alignment, mm } \\
\text { (SD) }\end{array}$ & $33(32)$ & $25(23)$ & 0.001 \\
\hline $\begin{array}{l}\text { Global positive sagittal mal- } \\
\text { alignment } \dagger\end{array}$ & 45 & 28 & $<0.001$ \\
\hline Mean PT, ${ }^{\circ}(\mathrm{SD})$ & $23(11)$ & $21(10)$ & $<0.001$ \\
\hline Mean PI-LL mismatch, ${ }^{\circ}$ (SD) & $13(21)$ & $3(14)$ & $<0.001$ \\
\hline
\end{tabular}

the best and worst outcome groups (Table 3). Patients in the worst outcome group had a higher rate of major complications compared with patients in the best outcome group ( $65 \%$ vs $30 \%, \mathrm{p}=0.001$ ), but the 2 groups had similar minor complication rates (55\% vs $49 \%$, respectively, $\mathrm{p}=0.020$ ). Compared with best outcome patients, at follow-up, those with the worst outcomes had greater leg and back pain $(\mathrm{p}<0.001)$, worse ODI and SRS-22 scores ( $\mathrm{p}$ $<0.001)$, modestly greater PI-LL mismatch $\left(9^{\circ}\right.$ vs $3^{\circ}, \mathrm{p}=$ 0.042 ), and trended toward a higher prevalence of positive sagittal malalignment $(\mathrm{p}=0.062)$ (Table 3$)$. Notably, the 2 groups did not differ significantly with regard to PT, global coronal alignment, or maximum coronal Cobb angle. The magnitude of change in deformity from baseline to follow-up was also compared between the best and worst outcome groups, and no significant differences were identified with regard to SVA, PT, PI-LL mismatch, or global coronal alignment (Table 3). The best outcome group had a slightly, but significantly greater correction of coronal Cobb angle $\left(-23^{\circ}\right.$ vs $\left.-17^{\circ}, \mathrm{p}=0.037\right)$.

Based on logistic regression analysis, only 3 parameters were incorporated into the final best-fit model, including baseline BMI $(p=0.037)$, follow-up SVA $(p=0.014)$, and baseline ODI $(\mathrm{p}<0.001)$ (Table 4$)$.

\section{Best and Worst Outcomes Based on SRS-22}

Of the 227 patients in the study cohort, 187 (82\%) had a baseline SRS-22 score $\leq 3.5$. For these 187 patients, the mean baseline SRS-22 score was 2.9 (SD 0.7, range 1.33.3) and the mean 2-year SRS-22 score was 3.7 (SD 0.8, range 1.6-5.0) (Fig. 1 right). Based on the SRS-22, the best outcome group (SRS-22 score $\geq 4.5$ ) consisted of 25 patients $(13 \%)$ and the worst outcome group (SRS-22 score $\leq$ 2.5 ) consisted of 27 patients (14\%) (Fig. 1 right). The worst outcome group had a mean baseline SRS-22 score of 2.2 (SD 0.7) and a mean 2-year follow-up SRS-22 score of 2.2 (SD 0.3) (Fig. 2 right). In contrast, the best outcome group 


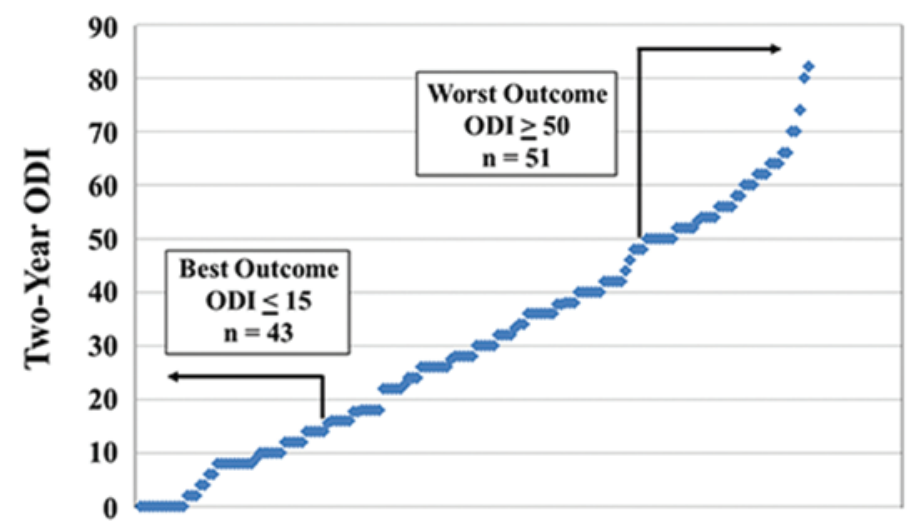

Patient

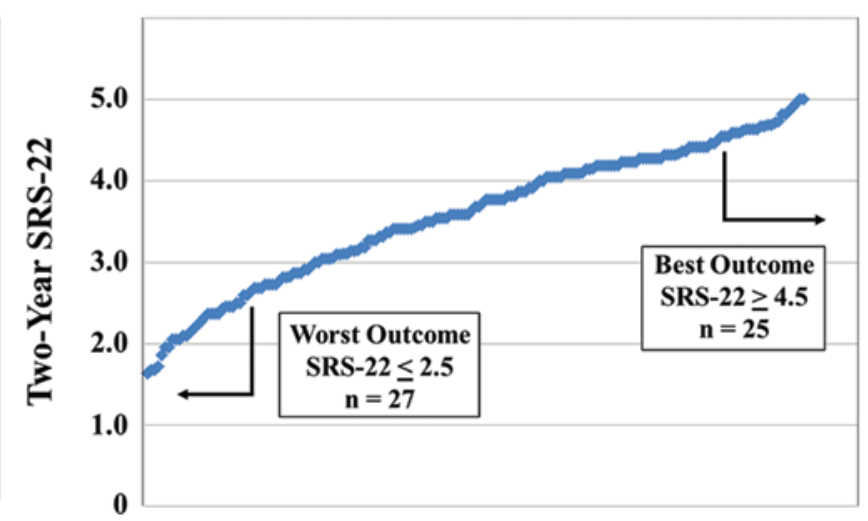

Patient

FIG. 1. Lowest to highest ODI and SRS-22 scores at 2 years following surgical treatment for spinal deformity, with cut-offs for best and worst outcomes indicated. Left: ODI scores for 162 adults; each patient had an ODI $\geq 30$ at baseline. Right: SRS-22 scores for 187 adults; each patient had an SRS-22 $\geq 3.5$ at baseline. Figure is available in color online only.

had a mean baseline SRS-22 of 3.0 (SD 0.4) that improved to a mean of 4.7 (SD 0.1) at 2-year follow-up (Fig. 2 right).

Of the total of 57 patients having the best outcome based on either the ODI or SRS-22, 11 were defined by both the ODI and SRS-22, 14 were defined based only on the SRS-22, and 32 were defined by the ODI only. Of the total of 57 patients having the worst outcome based on either the ODI or SRS-22, 21 were defined by both the ODI and SRS-22, 6 were defined based only on the SRS-22, and 30 were defined by the ODI only.

Univariate comparisons between the patients with best versus worst outcomes based on the SRS-22 are summarized in Table 5. Compared with patients with the best outcomes, at baseline, those with worst outcomes had worse SRS-22 ( $p<0.001)$, ODI ( $p<0.001)$, SRS-22 mental ( $\mathrm{p}<$ $0.001)$, and SF-36 mental component $(p<0.001)$ scores and had more back pain $(\mathrm{p}=0.006)$, greater comorbidities based on CCI $(p=0.012)$ and ASA $(p=0.004)$, higher prevalence of depression $(\mathrm{p}=0.028)$, higher prevalence of previous spine surgery $(\mathrm{p}=0.007)$, worse PI-LL mismatch ( $\mathrm{p}$ $=0.034)$, and a trend toward greater BMI $(\mathrm{p}=0.066)$. Best versus worst outcome groups did not differ significantly based on mean age (56 years vs 58 years, respectively, $\mathrm{p}$ $=0.684)$ or smoking status $(\mathrm{p}=0.340)$. Mean operative time and EBL did not differ significantly between the best and worst outcome groups (Table 5). Patients in the worst outcome group had a higher overall rate of combined minor and major complications compared with patients in the best outcome group ( $89 \%$ vs $56 \%, \mathrm{p}=0.012$ ). Compared with the patients with best outcomes, at follow-up, those with worst outcomes had greater leg and back pain $(\mathrm{p}<0.001)$ and worse ODI and SRS-22 scores $(\mathrm{p}<0.001)$ (Table 5). The 2 groups did not differ significantly with regard to prevalence of positive global sagittal malalign-
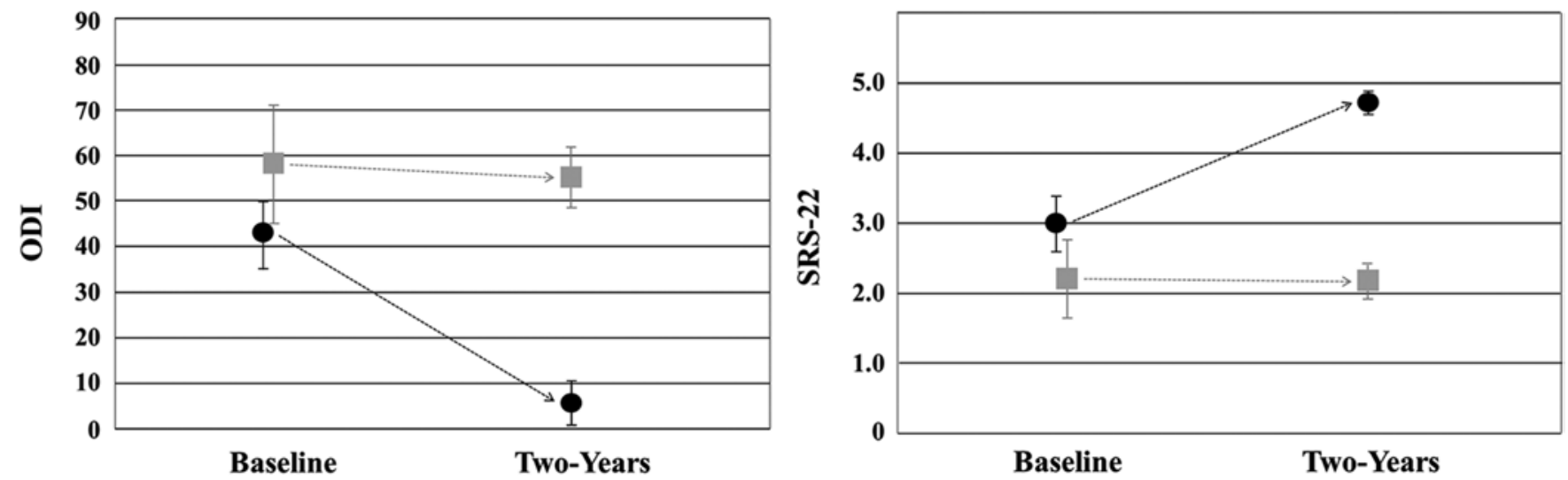

FIG. 2. Comparisons of the mean ODI and SRS-22 scores at baseline and 2 years following surgical treatment for ASD between the best clinical outcome and worst clinical outcome subgroups. Left: Comparison of mean ODI scores between the 2 groups of patients are shown, with black circles representing the subgroup with the best clinical outcome based on the ODI (defined as ODI score at 2 years $\leq 15 ; n=43$ ) and gray squares representing the subgroup with the worst clinical outcome based on the ODI (defined as ODI score at 2 years $\geq 50 ; n=51$ ); each patient had an ODI score $\geq 30$ at baseline. Error bars represent SDs. Right: Comparison of mean SRS-22 scores between 2 groups of patients are shown, with black circles representing the subgroup with the best clinical outcome based on the SRS-22 (defined as SRS-22 score at 2 years $\geq 4.5 ; n=25$ ) and gray squares representing the subgroup with the worst clinical outcome based on the SRS-22 (defined as SRS-22 score at 2 years $\leq$ $2.5 ; n=27)$; each patient had an SRS-22 $\leq 3.5$ at baseline. Error bars represent SDs. 
TABLE 3. Univariate analysis of baseline, operative, and follow-up parameters between patients with the best versus the worst outcomes based on the ODI following surgery for adult spinal deformity

\begin{tabular}{|c|c|c|c|}
\hline Parameters & Worst $(n=51)$ & Best $(n=43)$ & p Value* \\
\hline \multicolumn{4}{|l|}{ Baseline } \\
\hline $\mathrm{M} / \mathrm{F}$ & $10: 41$ & $6: 37$ & 0.583 \\
\hline Mean age, yrs (SD) & $60(10)$ & $57(13)$ & 0.138 \\
\hline Mean BMI (SD) & $30(6)$ & $26(5)$ & 0.002 \\
\hline Smoker (\%) & 4 & 12 & 0.247 \\
\hline Depression (\%) & 43 & 21 & 0.028 \\
\hline Mean CCl (SD) & $1.7(1.6)$ & $1.2(1.1)$ & 0.082 \\
\hline Mean ASA grade (SD) & $2.6(0.6)$ & $2.6(0.5)$ & 0.895 \\
\hline Prior spine surgery (\%) & 61 & 40 & 0.059 \\
\hline Mean leg pain score (SD) & $5.1(3.0)$ & $5.1(3.6)$ & 0.984 \\
\hline Mean back pain score (SD) & $8.3(1.6)$ & $7.2(1.9)$ & 0.003 \\
\hline ODI (SD) & $59(14)$ & $43(9)$ & $<0.001$ \\
\hline SRS-22 (SD) & $2.2(0.5)$ & $2.9(0.5)$ & $<0.001$ \\
\hline SRS-22 mental subscore (SD) & $2.9(0.9)$ & $3.6(0.8)$ & $<0.001$ \\
\hline SF-36 mental component score (SD) & $37.9(12.2)$ & $47.6(12.7)$ & $<0.001$ \\
\hline Global positive sagittal malalignment† & 69 & 37 & 0.009 \\
\hline Mean PT, ${ }^{\circ}(\mathrm{SD})$ & $27(10)$ & $24(9)$ & 0.154 \\
\hline Mean PI-LL mismatch, ${ }^{\circ}(\mathrm{SD})$ & $23(22)$ & $15(20)$ & 0.063 \\
\hline Mean coronal alignment, mm (SD) & $36(29)$ & $32(29)$ & 0.507 \\
\hline Max coronal Cobb angle, ${ }^{\circ}$ (SD) & $39(23)$ & $44(17)$ & 0.242 \\
\hline \multicolumn{4}{|l|}{ Operative } \\
\hline Operative time, hrs (SD) & $8.3(2.8)$ & $7.4(2.6)$ & 0.109 \\
\hline Estimated blood loss, L (SD) & $2.3(2.0)$ & $1.9(1.8)$ & 0.224 \\
\hline Major complications (\%) & 65 & 30 & 0.001 \\
\hline Minor complications (\%) & 55 & 49 & 0.679 \\
\hline Minor or major complications (\%) & 84 & 63 & 0.020 \\
\hline \multicolumn{4}{|l|}{ Follow-up } \\
\hline Mean leg pain score (SD) & $4.8(3.1)$ & $1.2(2.2)$ & $<0.001$ \\
\hline Mean back pain score (SD) & $6.2(2.9)$ & $1.5(1.7)$ & $<0.001$ \\
\hline ODI score (SD) & $55(9)$ & $7(5)$ & $<0.001$ \\
\hline SRS-22 score (SD) & $2.6(0.5)$ & $4.4(0.3)$ & $<0.001$ \\
\hline SRS-22 mental subscore (SD) & $3.1(1.0)$ & $4.3(0.5)$ & $<0.001$ \\
\hline SF-36 mental component score (SD) & $38.5(13.6)$ & $56.7(5.6)$ & $<0.001$ \\
\hline Global positive sagittal malalignment† & 61 & 37 & 0.062 \\
\hline Mean $\mathrm{PT},{ }^{\circ}(\mathrm{SD})$ & $24(10)$ & $22(9)$ & 0.405 \\
\hline Mean PI-LL mismatch, ${ }^{\circ}(\mathrm{SD})$ & $9(14)$ & $3(15)$ & 0.042 \\
\hline Mean coronal alignment, mm (SD) & $26(18)$ & $27(21)$ & 0.768 \\
\hline Max coronal Cobb angle, ${ }^{\circ}(\mathrm{SD})$ & $23(19)$ & $21(13)$ & 0.481 \\
\hline \multicolumn{4}{|l|}{ Change from baseline to $2 \mathrm{yrs}$} \\
\hline SVA, mm & $-35(73)$ & $-31(63)$ & 0.764 \\
\hline Mean PT, ${ }^{\circ}(\mathrm{SD})$ & $-4(10)$ & $-2(7)$ & 0.377 \\
\hline Mean PI-LL mismatch, ${ }^{\circ}(\mathrm{SD})$ & $-15(20)$ & $-12(16)$ & 0.428 \\
\hline Mean coronal alignment, mm (SD) & $-6(47)$ & $-10(39)$ & 0.715 \\
\hline Max coronal Cobb angle, ${ }^{\circ}$ (SD) & $-17(15)$ & $-23(15)$ & 0.037 \\
\hline
\end{tabular}

* Significant $p$ values are in bold.

$\dagger$ Percent with SVA $>5 \mathrm{~cm}$. 
ment, PT, global coronal alignment, or maximum coronal Cobb angle. The magnitude of change in deformity from baseline to follow-up was also compared between the best and worst outcome groups, and no significant differences were identified with regard to SVA, PT, PI-LL mismatch, or global coronal alignment (Table 5). The best outcome group had a modestly, but significantly greater correction of coronal Cobb angle $\left(-25^{\circ}\right.$ vs $\left.-16^{\circ}, \mathrm{p}=0.015\right)$.

Based on logistic regression analysis, only 3 parameters were incorporated into the final best-fit model, including baseline depression $(p=0.018)$, follow-up SVA $(p=0.035)$, and baseline ODI score $(\mathrm{p}=0.010)$ (Table 6).

\section{Discussion}

This study provides an assessment of the ranges of outcomes of surgery for adults with spinal deformity and provides comparisons between patients with the best and worst clinical outcomes at 2 years following surgery. Although the overall clinical outcomes measures at 2 years following surgery clearly demonstrated significant improvements in pain and disability based on multiple measures, the ranges of outcomes are remarkably broad. For example, ODI scores 2 years after surgery ranged from 0 (corresponding to essentially no disability) to 82 (corresponding to crippling back pain or being bed-bound). A similarly broad range was also identified for the SRS-22 scores. Comparing the patient groups with the best and worst outcomes based on the ODI and SRS-22 demonstrated several distinguishing features that included patient-related factors such as obesity and depression, surgical parameters such as complication rates, and deformity-related measures, including baseline and residual sagittal spinopelvic malalignment. Collectively, these data emphasize the range of clinical outcomes following ASD surgery and suggest that parameters distinguishing patients with the best versus worst outcomes are complex and multifactorial.

Two different standardized HRQOL instruments were used in the present study to determine best versus worst outcomes. The ODI is an index that was developed to measure the degree of disability in a patient with low-back pain. ${ }^{16}$ The questions are focused on function and concern intensity of pain, lifting, ability to care for oneself, ability to walk, ability to sit, sexual function, ability to stand, social life, sleep quality, and ability to travel. In contrast, the SRS-22 was developed through the Scoliosis Research Society as a disease-specific measure of HRQOL for spinal deformity patients. ${ }^{9}$ The SRS-22 focuses on 5 primary domains, including function, pain, self-image, mental health, and satisfaction. Despite the differing emphasis of the ODI and SRS-22, it is notable that there was substantial overlap in the factors that distinguished between the best and worst outcome patients defined by each questionnaire.

Smith and colleagues previously reported on comparisons of best versus worst outcomes following ASD surgery based on the Spinal Deformity Study Group (SDSG) database.$^{50}$ None of the patients in the present study, which drew patients from the ISSG database, overlap with this previous report, and there is only limited overlap between the contributing surgeons. In the previous report, baseline and perioperative factors that distinguished between the
TABLE 4. Multivariate analysis of factors distinguishing between the best and worst outcomes based on the ODI following surgery for adult spinal deformity*

\begin{tabular}{cccr}
\hline Parameter & OR & $95 \%$ Cl & p Value \\
\hline Baseline BMI & $0.893 \dagger$ & $0.803-0.993$ & 0.037 \\
\hline Follow-up SVA & $0.987 \ddagger$ & $0.976-0.997$ & 0.014 \\
\hline Baseline ODI & $0.914 \S$ & $0.872-0.959$ & $<0.001$ \\
\hline
\end{tabular}

\footnotetext{
* Stepwise binary logistic regression. See text for discussion of factors included in the analysis; results of best-fit model presented.

$\dagger$ OR for BMI is per BMI unit.

$\ddagger$ OR for SVA is per millimeter.

$\S$ OR for ODI is per ODI unit.
}

best and worst outcomes were also assessed based on the ODI and SRS-22 questionnaires and were predominantly patient-related factors, including BMI, depression/anxiety, smoking, and pain severity at baseline (Table 7).$^{50}$ Factors that did not distinguish between these groups included comorbidities, severity of deformity, operative parameters (EBL and operative time), and occurrence of complications. Importantly, the SDSG study, in contrast to the present study, did not include assessment of pelvic parameters, including PT and PI-LL mismatch. In the SDSG analysis, there were sufficient numbers of younger patients (18-45 years) to enable separate assessments of outcomes based on age groups (18-45 and 46-85 years). Although there were significant differences in deformity patterns, operative parameters, and complication rates between the younger and older patient groups, there was substantial overlap in the factors that distinguished the best and worst outcome patients between the age groups.

In the present study, $25 \%$ of the overall cohort had a diagnosis of depression at baseline. This high rate of depression likely relates to the impact of the spinal deformity on quality of life. These patients are, by inclusion criteria, those who have not sufficiently responded to nonoperative therapies and who have reached a point at which their spinal pathology has such significant impact that they are preparing for surgical treatment. The diagnosis of depression at baseline was a significant distinguishing factor between those with the best and worst 2-year clinical outcomes based on the ODI and on the SRS-22. The best and worst outcome groups based on the ODI and on the SRS-22 were also distinguished on univariate analysis by other measures of mental health status, including both the SF-36 mental component score and the SRS-22 mental subscore. For the SRS-22, depression remained a significant distinguishing factor after adjusting for the effects of baseline SRS-22 score and for the occurrence of complications. Notably, in the SDSG study, the rate of depression was very similar to that of the present study, with $26 \%$ of the younger (18-45 years) and $26 \%$ of the older (46-85 years) having this diagnosis at baseline..$^{50}$ For the SDSG patients, depression was a significant distinguishing factor between the best and worst outcomes on both univariate and multivariate analyses. ${ }^{50}$ Poorer surgical outcomes have also been associated with depression for other spinal conditions, including lumbar stenosis, ${ }^{1}$ adolescent idiopathic scoliosis, ${ }^{14}$ and a broad range of lumbar pathologies. ${ }^{40} \mathrm{Col}-$ 
TABLE 5. Univariate analysis of baseline, operative, and follow-up parameters between patients with the best versus the worst outcomes based on the SRS-22 following surgery for ASD

\begin{tabular}{|c|c|c|c|}
\hline Parameters & Worst $(n=27)$ & Best $(n=25)$ & p Value ${ }^{*}$ \\
\hline \multicolumn{4}{|l|}{ Baseline } \\
\hline $\mathrm{M} / \mathrm{F}$ & $7: 20$ & $4: 21$ & 0.503 \\
\hline Mean age, yrs (SD) & $58(11)$ & $56(15)$ & 0.684 \\
\hline Mean BMI (SD) & $29(6)$ & $26(4)$ & 0.066 \\
\hline Smoker (\%) & 4 & 13 & 0.340 \\
\hline Depression (\%) & 67 & 8 & $<0.001$ \\
\hline Mean CCl (SD) & $1.9(1.9)$ & $0.8(1.1)$ & 0.012 \\
\hline Mean ASA grade (SD) & $2.6(0.6)$ & $2.0(0.8)$ & 0.004 \\
\hline Prior spine surgery (\%) & 67 & 28 & 0.007 \\
\hline Mean leg pain score (SD) & $5.0(3.1)$ & $3.8(3.2)$ & 0.172 \\
\hline Mean back pain score (SD) & $8.2(1.8)$ & $6.7(2.0)$ & 0.006 \\
\hline ODI score (SD) & $56(20)$ & $37(13)$ & $<0.001$ \\
\hline SRS-22 score (SD) & $2.2(0.6)$ & $3.0(0.4)$ & $<0.001$ \\
\hline SRS-22 mental subscore (SD) & $2.7(0.9)$ & $3.9(0.8)$ & $<0.001$ \\
\hline SF-36 mental component score (SD) & $34.0(13.5)$ & $52.0(13.8)$ & $<0.001$ \\
\hline Global positive sagittal malalignment† & 59 & 36 & 0.173 \\
\hline Mean PT, ${ }^{\circ}(\mathrm{SD})$ & $26(10)$ & $24(8)$ & 0.376 \\
\hline Mean PI-LL mismatch, ${ }^{\circ}(\mathrm{SD})$ & $23(25)$ & $9(18)$ & 0.034 \\
\hline Mean coronal alignment, mm (SD) & $35(33)$ & $24(25)$ & 0.192 \\
\hline Max coronal Cobb angle, ${ }^{\circ}$ (SD) & $38(25)$ & $49(19)$ & 0.076 \\
\hline \multicolumn{4}{|l|}{ Operative } \\
\hline Operative time, hrs (SD) & $7.8(2.7)$ & $7.3(3.2)$ & 0.496 \\
\hline Estimated blood loss, L (SD) & $2.1(1.6)$ & $1.7(1.1)$ & 0.354 \\
\hline Major complication (\%) & 59 & 32 & 0.058 \\
\hline Minor complication (\%) & 52 & 36 & 0.278 \\
\hline Minor or major complication (\%) & 89 & 56 & 0.012 \\
\hline \multicolumn{4}{|l|}{ Follow-up } \\
\hline Mean leg pain score (SD) & $4.3(3.5)$ & $0.7(1.5)$ & $<0.001$ \\
\hline Mean back pain score (SD) & $7.3(2.8)$ & $0.6(1.3)$ & $<0.001$ \\
\hline ODI score (SD) & $56(13)$ & $6(7)$ & $<0.001$ \\
\hline SRS-22 score (SD) & $2.2(0.3)$ & $4.7(0.1)$ & $<0.001$ \\
\hline SRS-22 mental subscore (SD) & $2.4(0.7)$ & $4.7(0.3)$ & $<0.001$ \\
\hline SF-36 mental component score (SD) & $30.0(12.9)$ & $60.1(3.2)$ & $<0.001$ \\
\hline Global positive sagittal malalignment† & 44 & 24 & 0.158 \\
\hline Mean $\mathrm{PT},{ }^{\circ}(\mathrm{SD})$ & $24(9)$ & $24(9)$ & 0.998 \\
\hline Mean PI-LL mismatch, ${ }^{\circ}(\mathrm{SD})$ & $10(14)$ & $6(13)$ & 0.231 \\
\hline Mean coronal alignment, mm (SD) & $24(19)$ & $33(23)$ & 0.113 \\
\hline Max coronal Cobb angle, ${ }^{\circ}(\mathrm{SD})$ & $23(18)$ & $24(18)$ & 0.862 \\
\hline \multicolumn{4}{|l|}{ Change from baseline to $2 \mathrm{yrs}$} \\
\hline SVA, mm & $-35(86)$ & $-8(54)$ & 0.380 \\
\hline Mean PT, ${ }^{\circ}(\mathrm{SD})$ & $-3(8)$ & $0(6)$ & 0.124 \\
\hline Mean PI-LL mismatch, ${ }^{\circ}(\mathrm{SD})$ & $-14(23)$ & $-4(22)$ & 0.108 \\
\hline Mean coronal alignment, mm (SD) & $-3(54)$ & $-9(35)$ & 0.679 \\
\hline Max coronal Cobb angle, ${ }^{\circ}$ (SD) & $-16(13)$ & $-25(14)$ & 0.015 \\
\hline
\end{tabular}

* Significant $p$ values are in bold.

$\dagger$ Percent with SVA $>5 \mathrm{~cm}$. 
TABLE 6. Multivariate analysis of factors distinguishing between the best and worst outcomes based on the SRS-22 score following surgery for ASD*

\begin{tabular}{lccc}
\hline \multicolumn{1}{c}{ Parameter } & OR & 95\% Cl & p Value \\
\hline Baseline depression & $0.081 \dagger$ & $0.010-0.651$ & 0.018 \\
\hline $\begin{array}{c}\text { Complication (minor \&/or } \\
\text { major) }\end{array}$ & $9.012 \ddagger$ & $1.166-69.628$ & 0.035 \\
\hline Baseline SRS-22 score & $10.641 \S$ & $1.760-64.335$ & 0.010 \\
\hline
\end{tabular}

* Stepwise binary logistic regression. See text for discussion of factors included in the analysis; results of best-fit model presented.

$\dagger \mathrm{OR}$ for $\mathrm{BMI}$ is per BMI unit.

$\ddagger$ OR for SVA is per millimeter.

$\S$ OR for ODI is per ODI unit.

lectively, these data strongly suggest that optimization of treatment for depression should be pursued for adults with spinal deformity, and that management of depression may have impact on the clinical success of surgical treatment.

The mean BMI of the overall patient cohort in the present study was 27 , which corresponds to the "overweight" category. ${ }^{54}$ Although this may simply be reflective of the obesity issues facing many developed countries, it may also reflect the impact of pain and disability from spinal deformity on patient activity levels. In the present study, baseline BMI was a significant distinguishing factor between the patient groups with the best and worst clinical outcomes based on ODI and remained a significant distinguishing factor on multivariate analysis after adjusting for the effects of baseline ODI and follow-up SVA. In the SDSG study, baseline BMI was also a significant distinguishing factor between the best and worst outcome groups. ${ }^{50}$ Although previous reports have suggested that obese patients treated surgically for degenerative lumbar disease do not necessarily have poorer outcomes than nonobese patients, $4,15,20$ a recent report focused on spinal fusions involving 5 or more spinal levels has shown significant negative impact of obesity on clinical outcomes..$^{32}$ It is possible that obesity may have greater impact on recovery, rehabilitation, and long-term clinical outcomes for larger surgical procedures, such as those for spinal deformity, than for more limited procedures for degenerative conditions.

Previous reports have suggested that the occurrence of complications has only limited impact on clinical outcomes for ASD surgery, including the SDSG study that assessed best versus worst outcomes. ${ }^{24,49,50}$ In a study by Bridwell and colleagues that focused on outcomes for ASD surgery, it was noted that patients who had a major complication still experienced significant improvement in clinical outcomes measures but that there was a trend toward a smaller incremental improvement at 2-year follow-up in this patient group compared with those patients who did not have a major complication. ${ }^{10}$ In a subsequent report, the same authors documented the 3- to 5-year follow-up of this cohort and noted a significant impact of complications based on ODI and SRS scores at this longer-term follow-up. ${ }^{8}$ In the present study, the occurrence of complications, especially major complications, was a significant distinguishing factor between patients with the best and worst outcomes. These data, in combination with those of
TABLE 7. Summary of preoperative/operative and follow-up parameters that distinguished between the best and worst outcomes following surgery for ASD based on the present study from the ISSG database and a previous report from the SDSG database ${ }^{48}$

\begin{tabular}{|c|c|}
\hline ISSG & SDSG \\
\hline Preoperative/Operative & Preoperative/Operative \\
\hline \multicolumn{2}{|c|}{ Depression/anxiety } \\
\hline \multicolumn{2}{|c|}{ Mean BMI } \\
\hline \multicolumn{2}{|c|}{ Mean back pain score } \\
\hline \multicolumn{2}{|c|}{ Mean leg pain score } \\
\hline$S V A>5 \mathrm{~cm}$ & Age \\
\hline Comorbidities & Smoking \\
\hline \multicolumn{2}{|l|}{ Prior spine surgery } \\
\hline \multicolumn{2}{|l|}{ Major complications } \\
\hline Follow-Up & Follow-Up \\
\hline \multicolumn{2}{|c|}{ Mean back pain score } \\
\hline \multicolumn{2}{|c|}{ Mean leg pain score } \\
\hline PI-LL mismatch & \\
\hline
\end{tabular}

Bridwell and colleagues, suggest that the impact of major complications on clinical outcomes may not be as benign as previously reported, especially when assessing differences between patient groups at the extremes (best and worst) of outcomes measures.

Since the time that patients were accrued into the SDSG database, ${ }^{50}$ recognition of the importance of sagittal spinal alignment and pelvic parameters has greatly increased. $3,7,21,22,25-31,35-39,41,44,45,48,51,52$ Although patient-related factors, including BMI, depression, and baseline levels of pain and disability, seemed to dominate the distinguishing factors between best and worst outcomes, sagittal spinopelvic alignment parameters were also evident. Residual positive sagittal malalignment (SVA) was a significant distinguishing factor on multivariate analysis, which is consistent with previous reports that have documented negative impact of elevated SVA on HRQOL. ${ }^{22,27,37}$ In addition, the PI-LL mismatch, a parameter with previously reported strong correlations to HRQOL measures,${ }^{37}$ was also a significant distinguishing factor between best and worst outcome patients on univariate analyses.

Although the present study suggests multiple factors associated with a greater likelihood of a patient with ASD having a poor outcome with surgery, these factors alone should not necessarily preclude such patients from being offered surgery. When contemplating surgical treatment, there are many other factors that should also be considered, including the overall severity of symptoms, impact of the symptoms on functionality and quality of life, health status of the patient, and the willingness of the patient to accept the risks of surgery. ${ }^{46,50}$ The factors distinguishing between best and worst outcomes may provide opportunities for preoperative patient preparation. For example, optimization of treatment for depression and efforts to reduce excess weight preoperatively may mitigate the possible impact of these factors on outcomes. In addition, the distinguishing factors may also be helpful for preoperative 
patient counseling, including discussions regarding realistic outcomes expectations.

Strengths of the present study include the use of a prospectively collected, multicenter database, standardized assessment of radiographic parameters at a single core institution, and inclusion of spinopelvic alignment measures. The primary limitation of the study is the retrospective design. In addition, although the overall number of patients in the study cohort was large, the numbers of patients compared between the best and worst outcome groups was relatively small, owing to the selection of the subsets of patients at the extremes of the outcome spectrum. These small patient groups limited the extent to which complex multivariate modeling could be performed.

\section{Conclusions}

Few studies have specifically addressed factors that distinguish between the best versus worst clinical outcomes for ASD surgery. In this study, baseline and perioperative factors distinguishing between the best and worst outcomes for ASD surgery included several patient factors (baseline depression, BMI, comorbidities, and disability) as well as residual deformity (SVA) and occurrence of complications. These findings suggest factors that may warrant greater awareness and optimization to achieve optimal surgical outcomes for ASD patients.

\section{References}

1. Aalto TJ, Malmivaara A, Kovacs F, Herno A, Alen M, Salmi L, et al: Preoperative predictors for postoperative clinical outcome in lumbar spinal stenosis: systematic review. Spine (Phila Pa 1976) 31:E648-E663, 2006

2. Aebi M: The adult scoliosis. Eur Spine J 14:925-948, 2005

3. Ames CP, Smith JS, Scheer JK, Bess S, Bederman SS, Deviren $\mathrm{V}$, et al: Impact of spinopelvic alignment on decision making in deformity surgery in adults: A review. J Neurosurg Spine 16:547-564, 2012

4. Andreshak TG, An HS, Hall J, Stein B: Lumbar spine surgery in the obese patient. J Spinal Disord 10:376-379, 1997

5. Baldus C, Bridwell KH, Harrast J, Edwards C II, Glassman S, Horton W, et al: Age-gender matched comparison of SRS instrument scores between adult deformity and normal adults: are all SRS domains disease specific? Spine 33:2214-2218, 2008

6. Bess S, Boachie-Adjei O, Burton D, Cunningham M, Shaffrey C, Shelokov A, et al: Pain and disability determine treatment modality for older patients with adult scoliosis, while deformity guides treatment for younger patients. Spine 34:2186-2190, 2009

7. Blondel B, Schwab F, Ungar B, Smith J, Bridwell K, Glassman S, et al: Impact of magnitude and percentage of global sagittal plane correction on health-related quality of life at 2-years follow-up. Neurosurgery 71:341-348, 2012

8. Bridwell KH, Baldus C, Berven S, Edwards C II, Glassman $\mathrm{S}$, Hamill C, et al: Changes in radiographic and clinical outcomes with primary treatment adult spinal deformity surgeries from two years to three- to five-years follow-up. Spine 35:1849-1854, 2010

9. Bridwell KH, Berven S, Glassman S, Hamill C, Horton WC III, Lenke LG, et al: Is the SRS-22 instrument responsive to change in adult scoliosis patients having primary spinal deformity surgery? Spine (Phila Pa 1976) 32:2220-2225, 2007

10. Bridwell KH, Glassman S, Horton W, Shaffrey C, Schwab F, Zebala LP, et al: Does treatment (nonoperative and operative) improve the two-year quality of life in patients with adult symptomatic lumbar scoliosis: a prospective multicenter evidence-based medicine study. Spine (Phila Pa 1976) 34:2171-2178, 2009

11. Carreon LY, Puno RM, Dimar JR II, Glassman SD, Johnson JR: Perioperative complications of posterior lumbar decompression and arthrodesis in older adults. J Bone Joint Surg Am 85-A:2089-2092, 2003

12. Champain S, Benchikh K, Nogier A, Mazel C, Guise JD, Skalli W: Validation of new clinical quantitative analysis software applicable in spine orthopaedic studies. Eur Spine J 15:982-991, 2006

13. Charlson ME, Pompei P, Ales KL, MacKenzie CR: A new method of classifying prognostic comorbidity in longitudinal studies: development and validation. J Chronic Dis 40:373383, 1987

14. Clayson D, Mahon B, Levine DB: Preoperative personality characteristics as predictors of postoperative physical and psychological patterns in scoliosis. Spine (Phila Pa 1976) 6:9-12, 1981

15. Djurasovic M, Bratcher KR, Glassman SD, Dimar JR, Carreon LY: The effect of obesity on clinical outcomes after lumbar fusion. Spine (Phila Pa 1976) 33:1789-1792, 2008

16. Fairbank JC, Couper J, Davies JB, O'Brien JP: The Oswestry low back pain disability questionnaire. Physiotherapy 66:271-273, 1980

17. Fairbank JC, Pynsent PB: The Oswestry Disability Index. Spine (Phila Pa 1976) 25:2940-2952, 2000

18. Fu KM, Rhagavan P, Shaffrey CI, Chernavvsky DR, Smith JS: Prevalence, severity, and impact of foraminal and canal stenosis among adults with degenerative scoliosis. Neurosurgery 69:1181-1187, 2011

19. Fu KM, Smith JS, Sansur CA, Shaffrey CI: Standardized measures of health status and disability and the decision to pursue operative treatment in elderly patients with degenerative scoliosis. Neurosurgery 66:42-47, 2010

20. Gepstein R, Shabat S, Arinzon ZH, Berner Y, Catz A, Folman Y: Does obesity affect the results of lumbar decompressive spinal surgery in the elderly? Clin Orthop Relat Res (426):138-144, 2004

21. Glassman SD, Berven S, Bridwell K, Horton W, Dimar JR: Correlation of radiographic parameters and clinical symptoms in adult scoliosis. Spine (Phila Pa 1976) 30:682-688, 2005

22. Glassman SD, Bridwell K, Dimar JR, Horton W, Berven S, Schwab F: The impact of positive sagittal balance in adult spinal deformity. Spine (Phila Pa 1976) 30:2024-2029, 2005

23. Glassman SD, Carreon LY, Shaffrey CI, Polly DW, Ondra SL, Berven SH, et al: The costs and benefits of nonoperative management for adult scoliosis. Spine (Phila Pa 1976) 35:578-582, 2010

24. Glassman SD, Hamill CL, Bridwell KH, Schwab FJ, Dimar JR, Lowe TG: The impact of perioperative complications on clinical outcome in adult deformity surgery. Spine (Phila Pa 1976) 32:2764-2770, 2007

25. Klineberg E, Schwab F, Smith JS, Gupta MC, Lafage V, Bess S: Sagittal spinal pelvic alignment. Neurosurg Clin N Am 24:157-162, 2013

26. Lafage V, Bharucha NJ, Schwab F, Hart RA, Burton D, Boachie-Adjei O, et al: Multicenter validation of a formula predicting postoperative spinopelvic alignment. J Neurosurg Spine 16:15-21, 2012

27. Lafage V, Schwab F, Patel A, Hawkinson N, Farcy JP: Pelvic tilt and truncal inclination: two key radiographic parameters in the setting of adults with spinal deformity. Spine (Phila Pa 1976) 34:E599-E606, 2009

28. Lafage V, Schwab F, Skalli W, Hawkinson N, Gagey PM, Ondra S, et al: Standing balance and sagittal plane spinal de- 
formity: analysis of spinopelvic and gravity line parameters. Spine (Phila Pa 1976) 33:1572-1578, 2008

29. Lafage V, Smith JS, Bess S, Schwab FJ, Ames CP, Klineberg E, et al: Sagittal spino-pelvic alignment failures following three column thoracic osteotomy for adult spinal deformity. Eur Spine J 21:698-704, 2012

30. Legaye J, Duval-Beaupère G: Sagittal plane alignment of the spine and gravity: a radiological and clinical evaluation. Acta Orthop Belg 71:213-220, 2005

31. Legaye J, Duval-Beaupère G, Hecquet J, Marty C: Pelvic incidence: a fundamental pelvic parameter for three-dimensional regulation of spinal sagittal curves. Eur Spine J 7:99-103, 1998

32. McClendon J Jr, Smith TR, Thompson SE, Sugrue PA, O'Shaughnessy BA, Ondra SL, et al: The impact of body mass index on hospital stay and complications after spinal fusion. Neurosurgery 74:42-50, 2014

33. O'Brien MF, Kuklo TR, Blanke K, Lenke L (eds): Spinal Deformity Study Group Radiographic Measurement Manual. Memphis, TN: Medtronic Sofamor Danek, 2005

34. Rillardon L, Levassor N, Guigui P, Wodecki P, Cardinne L, Templier A, et al: [Validation of a tool to measure pelvic and spinal parameters of sagittal balance.] Rev Chir Orthop Reparatrice Appar Mot 89:218-227, 2003 (Fr)

35. Schwab F, Lafage V, Patel A, Farcy JP: Sagittal plane considerations and the pelvis in the adult patient. Spine (Phila Pa 1976) 34:1828-1833, 2009

36. Schwab F, Patel A, Ungar B, Farcy JP, Lafage V: Adult spinal deformity-postoperative standing imbalance: how much can you tolerate? An overview of key parameters in assessing alignment and planning corrective surgery. Spine (Phila Pa 1976) 35:2224-2231, 2010

37. Schwab FJ, Blondel B, Bess S, Hostin R, Shaffrey CI, Smith JS, et al: Radiographical spinopelvic parameters and disability in the setting of adult spinal deformity: a prospective multicenter analysis. Spine (Phila Pa 1976) 38:E803-E812, 2013

38. Schwab FJ, Lafage V, Farcy JP, Bridwell KH, Glassman S, Shainline MR: Predicting outcome and complications in the surgical treatment of adult scoliosis. Spine (Phila Pa 1976) 33:2243-2247, 2008

39. Schwab FJ, Patel A, Shaffrey CI, Smith JS, Farcy JP, Boachie-Adjei O, et al: Sagittal realignment failures following pedicle subtraction osteotomy surgery: are we doing enough? Clinical article. J Neurosurg Spine 16:539-546, 2012

40. Slover J, Abdu WA, Hanscom B, Weinstein JN: The impact of comorbidities on the change in short-form 36 and Oswestry scores following lumbar spine surgery. Spine (Phila Pa 1976) 31:1974-1980, 2006

41. Smith JS, Bess S, Shaffrey CI, Burton DC, Hart RA, Hostin $\mathrm{R}$, et al: Dynamic changes of the pelvis and spine are key to predicting postoperative sagittal alignment after pedicle subtraction osteotomy: a critical analysis of preoperative planning techniques. Spine (Phila Pa 1976) 37:845-853, 2012

42. Smith JS, Fu KM, Urban P, Shaffrey CI: Neurological symptoms and deficits in adults with scoliosis who present to a surgical clinic: incidence and association with the choice of operative versus nonoperative management. J Neurosurg Spine 9:326-331, 2008

43. Smith JS, Kasliwal MK, Crawford A, Shaffrey CI: Outcomes, expectations, and complications overview for the surgical treatment of adult and pediatric spinal deformity. Spine Deform [in press], 2012

44. Smith JS, Klineberg E, Schwab F, Shaffrey CI, Moal B, Ames CP, et al: Change in classification grade by the SRSSchwab Adult Spinal Deformity Classification predicts impact on health-related quality of life measures: prospec- tive analysis of operative and nonoperative treatment. Spine (Phila Pa 1976) 38:1663-1671, 2013

45. Smith JS, Shaffrey CI, Ames CP, Demakakos J, Fu KM, Keshavarzi S, et al: Assessment of symptomatic rod fracture after posterior instrumented fusion for adult spinal deformity. Neurosurgery 71:862-867, 2012

46. Smith JS, Shaffrey CI, Berven S, Glassman S, Hamill C, Horton W, et al: Improvement of back pain with operative and nonoperative treatment in adults with scoliosis. Neurosurgery 65:86-94, 2009

47. Smith JS, Shaffrey CI, Berven S, Glassman S, Hamill C, Horton W, et al: Operative versus nonoperative treatment of leg pain in adults with scoliosis: a retrospective review of a prospective multicenter database with two-year follow-up. Spine (Phila Pa 1976) 34:1693-1698, 2009

48. Smith JS, Shaffrey CI, Fu KM, Scheer JK, Bess S, Lafage V, et al: Clinical and radiographic evaluation of the adult spinal deformity patient. Neurosurg Clin N Am 24:143-156, 2013

49. Smith JS, Shaffrey CI, Glassman SD, Berven SH, Schwab FJ, Hamill CL, et al: Risk-benefit assessment of surgery for adult scoliosis: an analysis based on patient age. Spine (Phila Pa 1976) 36:817-824, 2011

50. Smith JS, Shaffrey CI, Glassman SD, Carreon LY, Schwab FJ, Lafage V, et al: Clinical and radiographic parameters that distinguish between the best and worst outcomes of scoliosis surgery for adults. Eur Spine J 22:402-410, 2013

51. Smith JS, Singh M, Klineberg E, Shaffrey C, Lafage V, Schwab FJ, et al: Surgical treatment of pathological loss of lumbar lordosis (flatback) in the setting of normal sagittal vertical axis achieves similar clinical improvement as surgical treatment of elevated sagittal vertical axis. Clinical article. J Neurosurg Spine 21:160-170, 2014

52. Terran J, Schwab F, Shaffrey CI, Smith JS, Devos P, Ames $\mathrm{CP}$, et al: The SRS-Schwab adult spinal deformity classification: assessment and clinical correlations based on a prospective operative and nonoperative cohort. Neurosurgery 73:559-568, 2013

53. Ware JE Jr: SF-36 health survey update. Spine (Phila Pa 1976) 25:3130-3139, 2000

54. World Health Organization: Obesity: Preventing and Managing the Global Epidemic. Report of a WHO Consultation (WHO Technical Report Series 894). Geneva: World Health Organization, 2000

\section{Author Contributions}

Conception and design: Smith, Shaffrey, Lafage, Scheer, Bess, Ames. Acquisition of data: Smith, Shaffrey, Lafage, Schwab, Protopsaltis, Klineberg, Gupta, Hostin, Fu, Mundis, Kim, Deviren, Soroceanu, Hart, Burton, Bess, Ames. Analysis and interpretation of data: Smith, Lafage. Drafting the article: Smith. Critically revising the article: all authors. Reviewed submitted version of manuscript: all authors. Approved the final version of the manuscript on behalf of all authors: Smith. Statistical analysis: Smith. Administrative/technical/material support: Shaffrey, Bess.

\section{Supplemental Information}

\section{Previous Presentation}

This work was presented in part at the International Meeting for Advanced Spine Techniques (IMAST) in Valencia, Spain (July 16-19, 2014).

\section{Correspondence}

Justin S. Smith, Department of Neurosurgery, University of Virginia Health Sciences Center, Box 800212, Charlottesville, VA 22908. email: jss7f@virginia.edu. 